\title{
Prognostic utility of late gadolinium enhancement cardiac magnetic resonance imaging in coronary artery disease: a meta-analysis
}

\author{
Raymond $\mathrm{H} \mathrm{Chan}^{1 *}$, Alexander A Leung ${ }^{2}$, Warren J Manning ${ }^{1}$ \\ From 16th Annual SCMR Scientific Sessions \\ San Francisco, CA, USA. 31 January - 3 February 2013
}

\section{Background}

Late gadolinium enhancement (LGE) cardiac MR can identify injured or scarred myocardium. However its prognostic implication remains unclear.

\section{Objective}

We sought to quantify the risk of major adverse cardiovascular events (MACE) among patients with LGE and CAD.

\section{Methods}

Two reviewers conducted a systematic search of electronic databases (MEDLINE and EMBASE) and hand searched bibliographies. Reviewers extracted data in duplicate, evaluated the quality of the studies based on a 4 point scale, and calculated pooled estimates. Out of 579 unique records screened, 115 full-text articles were assessed for eligibility. We then performed a meta-analysis on 18 eligible studies which reported on the occurrence of MACE in patients with LGE detected after a myocardial infarction.

\section{Results}

A total of 4,438 patients were included in the analysis. The overall hazard ratio (HR) for MACE was 2.65
(95\% confidence intervals, CI, 1.98-3.56) for the presence of any LGE, with large amounts of heterogeneity between studies $\left(\mathrm{I}^{2}, 83.5 \%\right)$. Furthermore, there was a continuous relationship between risk and the amount of LGE detected. For every $10 \%$ of the left ventricular mass with LGE, the risk of MACE increased by $56 \%$ (HR 1.56/10\% LGE, 95\% CI 1.39-1.75; I2, 63.6\%). Pre-specified meta-regression analyses revealed that the HR for MACE decreased with declining ejection fraction ( $\mathrm{p}=0.02)$ when LGE was continuous, and was inversely related to age $(\mathrm{p}<0.001)$ when LGE was binary.

\section{Limitations}

Studies were heterogeneous with respect to patient characteristics and the definition of MACE, which may limit interpretability and generalizability.

\section{Conclusions}

The presence and extent of LGE are independent predictors of MACE in patients with prior myocardial infarction.

\section{Funding}

Nil. 


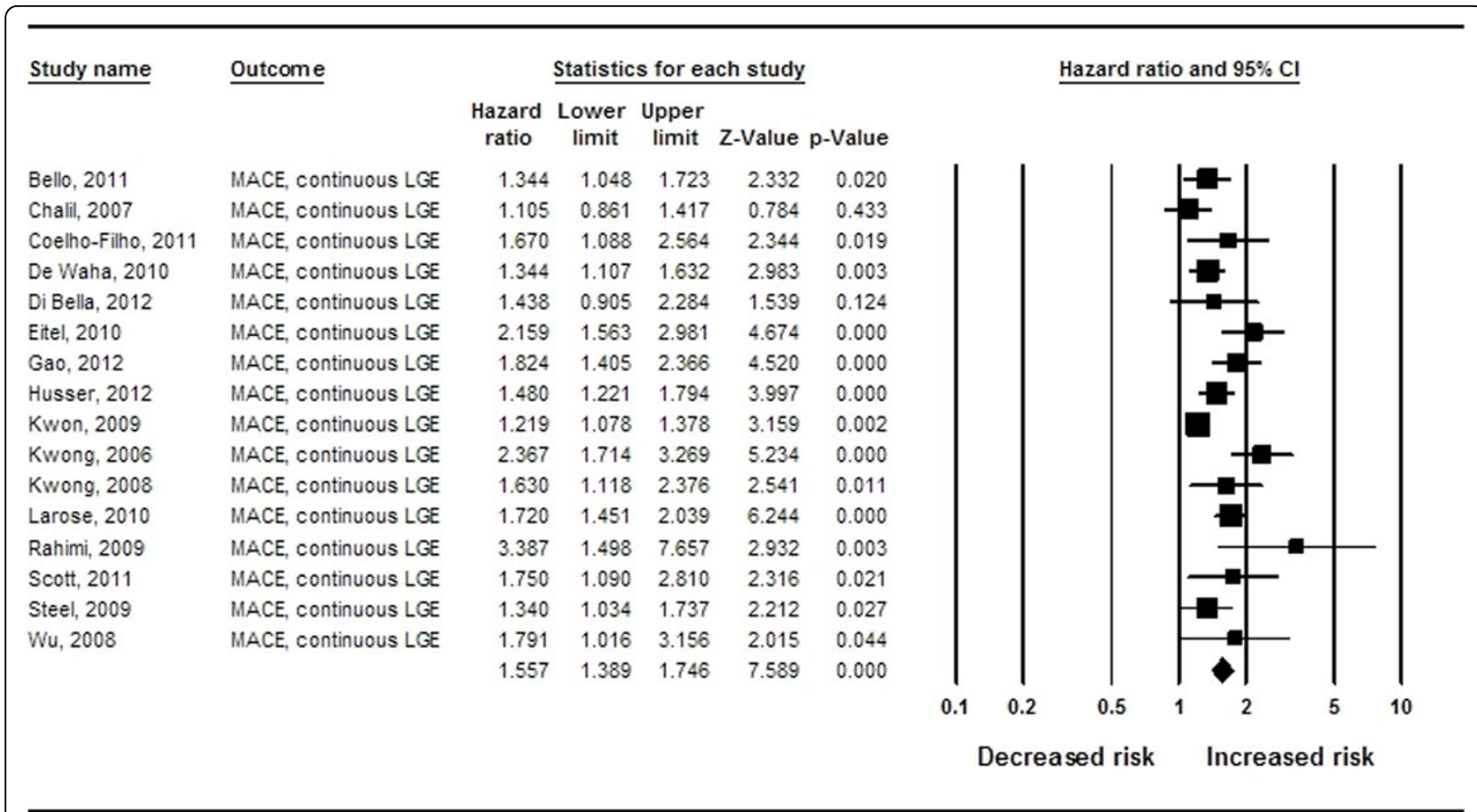

Meta Analysis

Figure 1 Forest Plot of risk for major adverse cardiovascular events as predicted by late gadolinium enhancement, expressed as HRs with $95 \%$ Cls.

Author details

${ }^{1}$ Beth Israel Deaconess Medical Center, Chestnut Hill, MA, USA. ${ }^{2}$ Brigham and Women's Hospital, Boston, MA, USA.

Published: 30 January 2013

doi:10.1186/1532-429X-15-S1-075

Cite this article as: Chan et al:: Prognostic utility of late gadolinium enhancement cardiac magnetic resonance imaging in coronary artery disease: a meta-analysis. Journal of Cardiovascular Magnetic Resonance 2013 15(Suppl 1):O75.
Submit your next manuscript to BioMed Central and take full advantage of:

- Convenient online submission

- Thorough peer review

- No space constraints or color figure charges

- Immediate publication on acceptance

- Inclusion in PubMed, CAS, Scopus and Google Scholar

- Research which is freely available for redistribution

Submit your manuscript at www.biomedcentral.com/submit 